\title{
Correction to: Experimental Nerve Plexus Root Avulsion and Spinal Cord Implantation
}

\section{Thomas Carlstedt and Mårten Risling}

\section{Correction to:}

Chapter 11 in : Mårten Risling and Johan Davidsson (eds.), Animal Models of Neurotrauma, Neuromethods, vol. 149, https://doi.org/10.1007/978-1-4939-9711-4_11

This book was inadvertently published without including the following reference:

“Hendriks WTJ, Eggers R,Carlstedt TP, Zaldumbide A. et al. (2007) Lentiviral vectormediated report gene expression in avulsed spinal ventral rroot is short-termed, but prolonged using an immune "stealth" transgene. Restor Neurol Neurosci 25:585-599".

It has now been inserted as reference 5 and cited in the text at the end of Figure 1 as follows:

"Sequence of photos taken during spinal nerve root dissection. In the last two photos the tips of the severed roots were stained before implantation (see Ref. [5])."

The updated online version of this chapter can be found at https://doi.org/10.1007/978-1-4939-9711-4_11 